\title{
Research on the Development of Educational Psychology under the New Media Model
}

\author{
Li Ting \\ Shaanxi Academy of Governance, Xi'an 710068, China
}

Keywords: Educational Psychology; New Media Model; Development Status; Education

\begin{abstract}
In recent years, the emergence of new media has had an immense impact on people's lives and lifestyles. Under the new media model, unprecedented development and changes have taken place in various industry sectors. In the same way, the field of educational psychology has also been associated with changes and innovations that have taken place under multiple new media approaches. As a bridge between psychology and pedagogy, educational psychology has been concerned by a wide range of fields. It uses scientific methodologies to take into account the two most important aspects of the education process, that is, systematic education methods and humanized psychological teaching, so that the cooperation between the two is more harmonious and effective. Under the new media model, the rational use of new media as a means to promote the development of educational psychology will be conducive to the advancement of educational reform. At the same time, this is an important issue facing the development of educational psychology.
\end{abstract}

\section{The Development of Educational Psychology in China under the New Media Model}

With the rapid development of informatization, new forms of media such as digital, broadcast, mobile phone, short message, wechat, and micro-blog appear under the conditions of new technologies. All of these forms have an impact on the field of educational psychology. Diversified ideological trends and diversified forms of media have made educational psychology a lot of new research hotspots in its own field. Due to the regional reflection and adaptability of culture, educational psychology has undergone a cross-cultural and trans-regional stage, which has allowed localization studies to enter the eyes of Chinese scholars. And under the influence of different educational backgrounds and historical and folklore factors, it gradually develops toward more local characteristics. In addition, with the continuous development of network technology, relevant scientific statistics and comprehensive survey methods are gradually applied to the research of educational psychology. These technologies have provided great convenience and accuracy for the study of educational psychology, which has greatly improved the efficiency of its own research.

Changes in the ideology, behavior, and other aspects of students in the current era are closely related to changes in society. It is precisely because of this complex social change and the continuous deepening of the educational reform system that the roles of educators and students are more complex than before. Therefore, under the background of the development of the new media model, the research of educational psychology will pay more attention to the possible problems in the actual education and teaching, further learn and absorb the latest theoretical results of psychology, and gradually innovate research methods and expand the research field. In addition, with the increasingly significant value of educational psychology in social practice, it has been applied in various fields, not just education. However, even educational psychology has a perfect system in theory itself, it is out of touch with reality in different areas of different practices, and it is difficult to connect with theory. The following will discuss the main issues faced by the current development of educational psychology in China, such as the monotony of research, or the lack of integration of theoretical and practical, and the lack of localization. 


\section{The Main Problems in the Development of Educational Psychology in China at Present}

The Development Is One-sided and the Research Method Is Slightly Single. One of the most significant problems in the development of current educational psychology is the one-sidedness and monotony of its teaching content. Because it is impossible to create a good paradigm for the overall system, coupled with the neglect of the human-centered practical teaching, it is difficult to combine the existing educational psychology with the current state of education in China, and rely mainly on the disciplines of natural sciences and applied research. Although for the progress of disciplines, diversified interdependence is more conducive to its own development, but the current educational psychology is lacking in the core concept, which to a certain extent has adversely affected its sustainable development. In addition, because of the different influences of different environments during the development period, the related research methods of educational psychology can not be well connected.

In the process of psychological activity research, traditional psychology mainly uses empirical research and phenomena analysis to study the subjective differences between people and objects. However, if such an imitative approach is used in practice teaching, it will inevitably ignore the complex relationship between people, and it is difficult to accurately recognize the human behavior and motivation.

Insufficient Combination of Theory and Practice. The basic research and applied research reflected in educational psychology each have their own strengths. In theory, the focus of educational psychology is more on practical application, and it has certain guiding and empirical significance on practical educational practice. In other words, educational psychology research that has been separated from practice will inevitably reflect different degrees of one-sidedness. However, from the actual development process of educational psychology, and even the current development status, the areas facing the educational psychology in China still focus on the theoretical level rather than the actual educational practice. This also makes it impossible for relevant theoretical research to achieve its effective significance for educational practice.

In general, the main reason for this situation lies in the vagueness of the positioning of educational psychology. Specifically speaking, the first is the disconnection between theory and application in the field of educational psychology, which makes the relevant research stick to the development of theory, but it is difficult to guide practice in a real sense. However, the practical work of the education sector lacks a certain theoretical basis, which makes it easy for the practical process to encounter certain obstacles, and it is difficult to improve efficiency. Secondly, the main application scope of the current educational psychology is mainly to serve the school, but it is rarely touched as the parent who has the most frequent contact with the educated person. Including in other fields, such as business, book compilations, training institutions, etc., have less consideration of the application of educational psychology, which limits the wide application of educational psychology from a very narrow scope.

Insufficient Depth of Localization Research. Intuitively speaking, educational psychology is introduced into China as an external subject and applied. Western educational psychology research results have a direct and far-reaching impact on educational psychology in China. This fundamentally determines that its localization will be achieved through learning from others and independent research in the development of educational psychology in China.

The problem of lack of localization in the development of educational psychology in our country is in fact inevitable. This is primarily because education psychology is a discipline that has been introduced from the West. At the time of introduction, it already possessed a relatively complete system and material foundation, so that the space for the development of this discipline in local development becomes even smaller. In addition, it is difficult to immediately adapt to China's traditional deeply ingrained education concepts and weak material foundations. Therefore, the research process of localization appears to be slow. On the other hand, due to the late start of educational psychology in our country, the emphasis on education has only been revived since the 1980s. However, it suffers from not having enough research results and materials, and enough research personnel. Therefore, in the face of urgent educational needs, it can only rely on and study 
the research results of foreign countries, leading to a lack of independence and characteristics of research topics and methods in local research.

\section{How to Use the New Media Model to Solve Problems in Educational Psychology}

Innovate Research Methods and Use New Media to Strengthen the Practical Application of Educational Psychology. Today, the application of cable networks, wireless networks, mobile phone, and other handheld media are gradually being widely accepted in the field of education. The functions embodied in these new media exactly complement the problems faced by the education sector, such as lack of information and poor communication. Similarly, these new media models have a certain degree of influence on the research of educational psychology. In terms of research methods, it is obviously difficult to achieve comprehensive and objective research by expanding educational psychology through only one method. Traditional research methods have their own advantages and disadvantages, and they should be selectively inherited. At present, under the influence of the new media model, research in educational psychology should be oriented toward a broader perspective. Actively learn and use the innovative thinking and research methods brought about by new technologies and methods to enhance the multi-dimensional development of this discipline. The rapid development of science and technology has extensive support for qualitative research. Its scientific survey and statistical methods have greatly saved the time and effort spent on traditional research and greatly increased the efficiency of research. For example, the information the researchers obtain through the Internet can provide the most comprehensive information in the shortest time. The computer database technology can integrate the breakthroughs and problems encountered in practice in educational psychology one by one, and become a large and accurate database, thus providing researchers with a more scientific practice.

Actively cooperate with the policy of education reform and participate in practical teaching with the help of new media. In recent years, China is in an important period of actively advancing education reform and promoting quality education in an all-round way. If contemporary educational psychology is to contribute to sustainable development on the basis of the intrinsic theory, it should be combined with China's current education reform to explore the theoretical research and practical problems of educational psychology. This will not only help to deepen the path of education reform, but also make it possible for educational psychology to develop itself. From the practical effect of educational psychology, in the past 20 years, its research results have clearly played a role in promoting the education sector. It coincides with the student personality development, intelligent development, and multiple development advocated in education reform. In addition, the effectiveness of teaching and the professional quality of teachers are also synchronized with their development.

Taking the importance of the practical significance of educational psychology, the practical application of educational psychology in the context of new media should show more flexibility. For example, in the education of colleges and universities, students should be encouraged to develop their personalities in life and broaden their thinking in learning. Students should participate in network practice and competitions in the right way, actively seek more practice and exercise opportunities for themselves and use new media methods more flexibly to achieve the purpose of educational psychology in practical learning.

Study on Theory and Application of Educational Psychology with Chinese Characteristics Based on Existing Theories. Based on the existing theoretical basis, especially the research results of educational psychology derived from the West, we continued to carry out theoretical and applied research on educational psychology with Chinese national characteristics and in line with the psychological characteristics of Chinese educators. This is the main way to solve the current lack of localization in educational psychology research. The indigenization of educational psychology research requires researchers to uphold the core concept of humanism in their research work. Starting from the researcher's position, they should accurately understand the psychological characteristics of Chinese people and the psychological changes in the process of education. In this way, we deeply study the commonalities and differences in the psychological state of people under 
different cultural backgrounds. And make it an entry point to explore the practical methodology of educational psychology in different countries and nationalities, it also contributes to the development of world education psychology.

The localization process of the development of educational psychology research must be based on the important theories of contemporary educational psychology. With the help of new scientific methods, the local educated groups are taken as the research object, combined with practical investigation and integration, so that the final research results have the overall characteristics to explain each individual's psychological and behavioral changes. Alternatively, individuals may be selected from local groups for individual research by taking surveys. The research results are used as the hypothesis theory, and the practice is used for verification and introduction. The essence of Chinese traditional education is combined with it to reflect the characteristics of educational psychology with local characteristics.

\section{Conclusion}

At present, educational psychology is at the critical stage of application in the education field in China. Therefore, under the background of the rapid development of economy and science and technology, how to use the existing new media model to improve actual results is the substantive goal of the development of educational psychology theory. At the same time, the perfection and development of theoretical research on educational psychology plays an indispensable role in guiding and facilitating the entire education field. In order to continuously make breakthroughs in educational achievements to meet the needs of social development for talent cultivation, educational psychology, which combines the psychological phenomena and teaching methods in the field of education, has a certain reference and guidance for the development of teaching. Therefore, we should fully apply the theory of educational development in educational psychology to various practices. Combining our country's national conditions and education status, we will make unremitting efforts for its localization and make greater progress in the development of educational psychology in our country both theoretically and practically.

\section{Reference}

[1] Q. Chen and J. W. Zhang. The Improvement of Educational Psychology Research Methods [J]. Education Research and Experiments, 2000(1).

[2] W. B. Peng. Educational Networking and Its Educational Psychology [J]. China Distance Education, 2001(2)

[3] D. J. Zhang. Educational Psychology [M]. Beijing: People's Education Press, 2005.

[4] T. Wang. Perspectives on the Current Issues in the Development of Educational Psychology in China $[\mathrm{J}]$. Journal of Southwest China Normal University: Humanities and Social Sciences, 2002(1).

[5] A. Q. Zhang. Review and Prospect of the Development of Educational Psychology in China in the 20th Century [J]. Journal of East China Normal University: Education \& Sciences, 1998(3).

[6] C. D. Lin. Ten Relations in the Study of Developmental Psychology and Educational Psychology [J]. Psychological Development and Education, 2005(1).

[7] C. F. Zhang. Educational Psychology [M]. Jinan: Shandong Education Press, 2000.

[8] C. X. Zhang. The Theory and Practice of Psychological Research on Native Cultural Orientation [J]. Psychological Science, 2004 (2): 420-422.

[9] D. J. Zhang and X. C. Xu. The Role of Educational Psychology in Promoting Education Reform in China in Recent 20 Years [J]. Psychological Science, 2005(6).

[10] X. X. Wang. Development History and Trend of Educational Psychology [J]. Journal of Liaoning Normal University: Social Sciences Edition, 2002(5). 